\title{
Retrofitting Options for Un-Reinforced Brick Wall Subjected to Impact Load
}

\author{
Norazman Mohamad Nor ${ }^{1, a}$, Mohd Azizul Mohd Noor ${ }^{1}$, \\ Mohammed Alias Yusof ${ }^{1, b}$, Ahmad Mujahid Ahmad Zaidi ${ }^{1, c}$, \\ and Shohaimi Abdullah ${ }^{1, d}$
}

\author{
${ }^{1}$ Faculty of Engineering, National Defence University of Malaysia, 57000 Kuala Lumpur, Malaysia. \\ aazman@upnm.edu.my, balias@upnm.edu.my, 'cmujahid@upnm.edu.my, \\ 'shohaimi@upnm.edu.my
}

\begin{abstract}
Keywords: Retrofitted Brick Wall, Blast Resistant Structure, Composites in Construction, FRP Reinforced Wall.
\end{abstract}

\begin{abstract}
In this research we investigate the possibility of enhancing the way brick walls can be retrofitted in an economical manner and become more resistant to blast impact. Retrofitting a method usually done on constructed walls; however, the same strengthening procedures can also be applied to a new construction project. In this research we investigate three methods of reinforcing brick walls against blast impact. First, reinforcing the brick layer using carbon fiber strips only without epoxy, with the fiber being placed on the bare bricks before it is plastered with mortar finishing, second, reinforcing the brick wall by placing CFRP onto the bare bricks and fixing with epoxy prior to finishing or being plastered over with mortar, and third, retrofitting the outer surface of a finished, or plastered, brick wall with CFRP and fixed with epoxy as is commonly done. The impact test was conducted using a drop weight released at a fixed height to simulate blast energy of an explosion. The effects of the test on all the samples were observed to identify failure patterns. Flexural testing was also conducted to observe how the samples perform under normal flexural loading. It was discovered that the second option, i.e. placing the CFRP on the bare bricks and fixing with epoxy before it is finished or plastered over with mortar, performs the best. This is due to the CFRP being firmly fixed before mortar finishing, causing the CFRP to be held steadily in place during the impact, thus, helping the wall to resist the impact load. With the third option, the CFRP was able to resist the impact but, as has been observed in other studies, the CFRP delaminates from the wall. The first option does not work very well since the mortar is unable to perform as well as the epoxy in holding the fiber to the wall to resist the impact force. Thus, for plastered brick walls, it is better suited for it to be reinforced by FRP under the finished mortar rather than on it, thus reducing the problem of delaminated FRP from the wall surface.
\end{abstract}

\section{Introduction}

In current times, in certain countries, structures such as buildings and bridges may become subject to terrorist bomb attacks. Therefore, these existing structures may need to be retrofitted for better resistance to and maximum protection against blast loading. One of the weakest parts of a building are the brick walls. Walls are designed to protect occupants from the external environment but not to withstand extreme loading such as from a blast impact. Therefore, the use of Carbon Fiber Reinforced Polymer (CFRP) to retrofit brick walls will be investigated to identify its role in resisting explosions and blast load impacts. CFRP is also expected to reduce spalling of wall debris, which can cause injuries to occupants in the walled space.

This research investigates the behavior of brick wall panels retrofitted with CFRP which are then subjected to sudden impact loads such as blast loading, as may be experienced in terrorist bomb attacks. In order to minimize property destruction, injuries and loss of human lives from these explosions, a method of strengthening wall structures is required. One of the primary strengths of 
CFRP is its ability to modify and improve the performance of structures and enhance that structure's strength. The primary function of carbon fiber is to carry loads along the length of the fiber sheet and to provide strength and stiffness where required.

Retrofitting is a method of strengthening, and improving the survivability of a particular structure by externally bonding the CFRP to particular structural members to ensure that the structure can withstand earthquakes, blast loading and impacts. Typically, CFRP is woven into a fabric, which is saturated with epoxy resin and applied to the surface of the component requiring the retrofit [1]. Effective use of carbon reinforced polymers could significantly increase the strength or blast resistance of these structures.

The objectives of this research are to investigate various retrofitting techniques using CFRP and to observe the behavior of the brick wall panel retrofitted with CFRP with attention to failure pattern and flexural strength under flexing and impact loads.

\section{Technique of Retrofitting}

Near Surface Mounted (NSM). NSM is one of the strengthening techniques for reinforced concrete structures. In the NSM technique, fiber reinforced polymer (FRP) rods are applied by placing these rods into grooves in the concrete cover of the tension region of strengthened concrete members. Initially the grooves are halfway filled with epoxy following which the FRP rods are placed into the grooves and pressed down to ensure that the epoxy completely fills the space between the rods and groove voids. The groove is then filled with more epoxy and lastly the concrete surface is leveled. This technique effectively increases both the flexural and shear strength of deficient reinforced concrete. This method is relatively simple and considerably enhances the bond of the mounted FRP reinforcements, therefore utilizing the material more effectively. [2,3]

FRP Strip. There are three ways of bonding the FRP strip i.e. either horizontally, vertically or diagonally. The strips are typically attached by adhesive bonding to the surface of the structural element such as beams, columns, walls and slabs. This method is time consuming because it takes days for surface preparation such as cleaning and smoothening of the concrete surface to ensure optimal bonding between the FRP strips and the structural element. If the concrete surface is not correctly prepared, the fiber strip will easily de-bond from the surface after the strips are installed. [4]

FRP Sheet. The application of FRP sheet is the commonest technique used nowadays. The sheet of FRP is cut to size then simply aligned in a single $\left(0^{\circ}\right)$ or dual direction $\left(0^{\circ}\right.$ and $\left.90^{\circ}\right)$, to improve the bending strength of the column and beam. Furthermore, to minimize the occurence of sheet rupture, the application of the FRP sheet must provide an anchorage between the sheets and the structural element [5]

The most effective bonding method is a FRP composite wrap [6]. To wrap the structure, each layer may have the fibers oriented in multiple directions such a 0 degree direction of first layer and 90 degree direction in second layer. This pattern can be repeated until the desired wrap thickness is achieved. In the case of brick walls, it may not be economical or even possible to wrap the wall.

\section{Preparation of Samples}

Fabrication of Samples. 24 samples of brick wall panel were fabricated as detailed in Table 1. The dimensions of each brick used was $210 \mathrm{~mm}$ length x $90 \mathrm{~mm}$ width x $65 \mathrm{~mm}$ height. From these 24 samples, 12 samples were fabricated for the impact test and 12 samples for the flexural strength test. 
Table 1. Sample Classifications.

\begin{tabular}{|c|c|c|c|c|}
\hline \multirow[t]{2}{*}{ Type } & \multirow[t]{2}{*}{ Sample } & \multirow{2}{*}{$\begin{array}{l}\text { Type of } \\
\text { Fiber }\end{array}$} & \multicolumn{2}{|c|}{ Quantity } \\
\hline & & & $\begin{array}{c}\text { Flexural } \\
\text { Strength Test }\end{array}$ & $\begin{array}{c}\text { Impact Load } \\
\text { Test }\end{array}$ \\
\hline 1 & Control (unretrofitted) & None & 3 & 3 \\
\hline 2 & $\begin{array}{l}\text { Retrofitted }\left(0^{\circ}\right) \text { on } \\
\text { masonry, without epoxy, } \\
\text { plastered with mortar }\end{array}$ & CFRP & 3 & 3 \\
\hline 3 & $\begin{array}{l}\text { Retrofitted }\left(0^{\circ}\right) \text { on } \\
\text { masonry with epoxy, } \\
\text { plastered with mortar }\end{array}$ & CFRP & 3 & 3 \\
\hline 4 & $\begin{array}{l}\text { Retrofitted }\left(0^{\circ}\right) \text { on } \\
\text { plastered wall with epoxy }\end{array}$ & CFRP & 3 & 3 \\
\hline
\end{tabular}

Bonding of CFRP Laminates onto the Brick Wall Panel. After a surface preparation process, carbon fiber laminates were cut to strips $700 \mathrm{~mm}$ long x $100 \mathrm{~mm}$ wide. Fiber strips were prepared for each sample and each strip consisted of three layers of fiber. The fiber strips were bonded with an orientation of $0^{\circ}$. Epoxy was applied to the panel's surface before the first layer of fiber laminate strips was applied. This is to obtain efficient bonding between the fiber strip and the mortared or brick surface. To ensure that there are no air voids trapped between the panel surface and the laminates, the fiber strips were applied using a roller. These specimen wall panels, retrofitted with CFRP, were left to cure at room temperature for several days before the test. Fig 1 shows the orientation of fiber bonded to the brick wall panel and fiber strip anchorage.
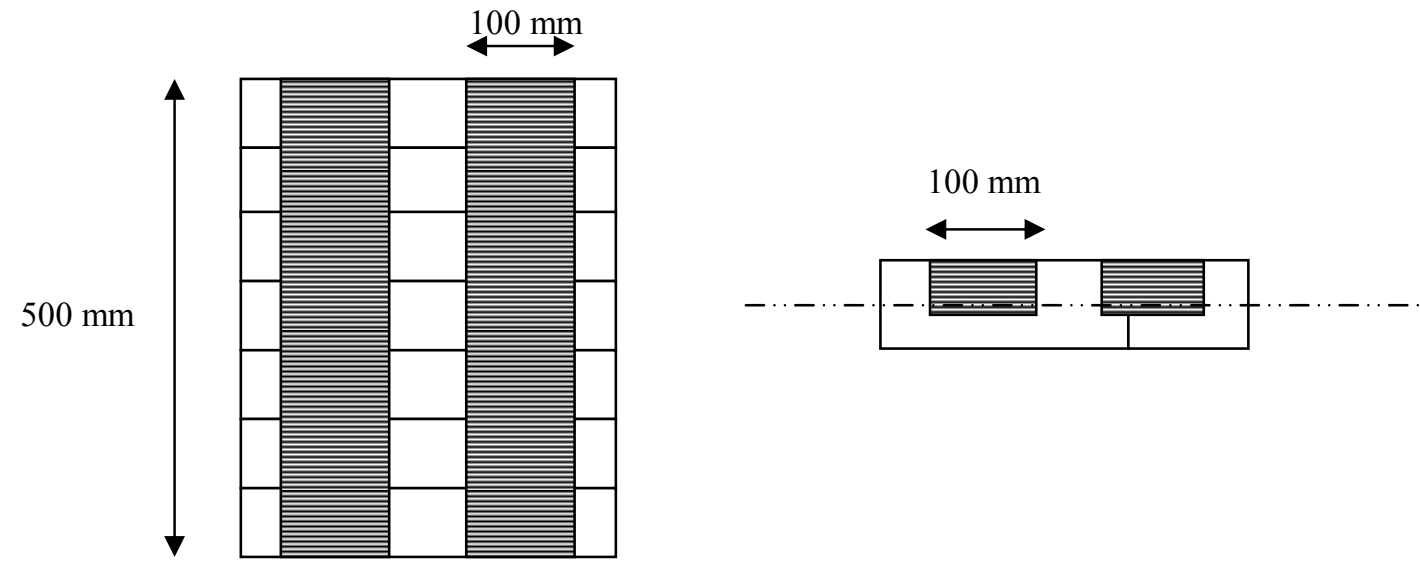

Figure 1. $0^{\circ}$ Fiber Bonded on the Brick Wall with End Anchorage. [7]

\section{Instrumentation and Testing}

Specimen Test. Four specimens of CFRP were prepared for the tensile strength test. The result of this test is shown in Table 2.

Table 2. Result of Carbon Fiber + Epoxy. [7]

\begin{tabular}{|c|c|c|c|c|}
\hline Sample & $\begin{array}{c}\text { Maximum } \\
\text { Load [N] }\end{array}$ & $\begin{array}{c}\text { Tensile Stress at } \\
\text { Break [MPa] }\end{array}$ & $\begin{array}{c}\text { Modulus of } \\
\text { Elasticity } \\
{[\mathbf{M P a}]}\end{array}$ & $\begin{array}{c}\text { Density, } \boldsymbol{\delta} \\
{\left[\mathbf{k g} / \mathbf{m}^{\mathbf{3}}\right]}\end{array}$ \\
\hline Mean & 26208.568 & 677.517 & 15173.9 & 2158.9 \\
\hline
\end{tabular}


Brick Test. Three clay bricks were tested using a Compression Testing Machine to get strength of the clay bricks. The results of this test are shown in Table 3.

Table 3. Strength of Clay Brick. [7]

\begin{tabular}{|c|c|c|}
\hline Brick Dimension & Sample & $\begin{array}{c}\text { Compressive Strength } \\
{\left[\mathbf{N} / \mathbf{m m}^{2}\right]}\end{array}$ \\
\hline $215 \mathrm{~mm} \times 102.5 \mathrm{~mm} \times 65 \mathrm{~mm}$ & Mean & 45.1 \\
\hline
\end{tabular}

Impact Load Test. The brick wall panels were tested through drop impact using a solid ball weighing $5.90 \mathrm{~kg}$. Fig 2 presents the test set-up for the impact test, and shows the after impact view of Brick Wall Panel Type 3. The height of the drop was obtained by computing the equivalent energy produced from a $1 \mathrm{~kg}$ TNT explosion with a stand-off distance of 0.5 meter from the target.

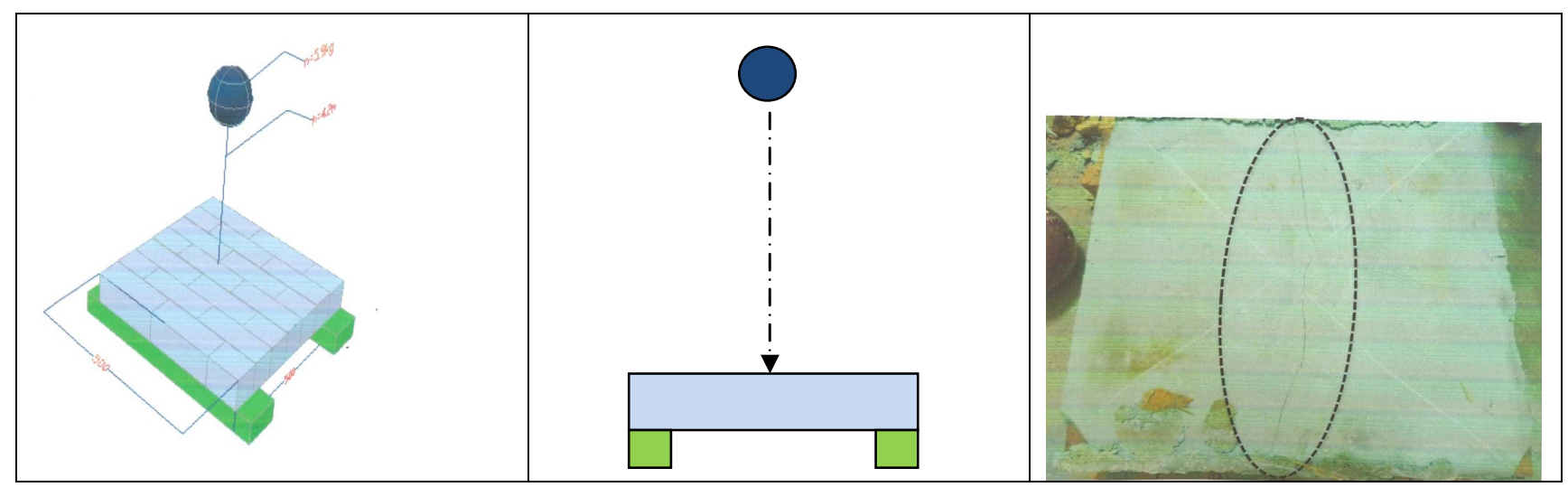

Figure 2. Test Set-Up for Drop Impact Test. [7]

A total of four different types of samples were tested. Each type of sample contained three individual wall panel samples. Results from the impact test are very consistent for each type of sample as is presented in Table 4.

Table 4. Result of Impact Test.

\begin{tabular}{|c|l|}
\hline $\begin{array}{c}\text { Sample } \\
\text { Type }\end{array}$ & \multicolumn{1}{c|}{ Failure pattern } \\
\hline 1 & $\begin{array}{l}\text { Heavily damaged. The brick wall panel was crushed at the center, at point of } \\
\text { impact, and with much displaced debris. }\end{array}$ \\
\hline 2 & $\begin{array}{l}\text { Heavily damaged. The brick wall panel cracked at the mortar joints and } \\
\text { broke into four pieces. The fiber strips were displaced from the mortar layer. }\end{array}$ \\
\hline 3 & $\begin{array}{l}\text { Hairline cracks on the surface finishing of the brick wall panel parallel to the } \\
\text { fiber strip axis. No cracks seen at the bottom part (tension face) of the panel. }\end{array}$ \\
\hline 4 & $\begin{array}{l}\text { Visible cracks appeared. The mortar layer cracked on the top part and along } \\
\text { the side of the panel parallel to fiber strip axis. CFRP debonding from the } \\
\text { panel but no damage to the CFRP noted. }\end{array}$ \\
\hline
\end{tabular}

\section{Flexural Strength Test}

For this test, there were 12 samples tested. Each sample type consisted of three individual specimens. This flexural strength test is in accordance with ASTM C78. Table 5 shows the results of the flexural strength test. 
Table 5. Results of the Flexural Strength Test [7]

\begin{tabular}{|c|c|c|c|}
\hline \multirow{2}{*}{$\begin{array}{c}\text { Sample } \\
\text { Type }\end{array}$} & \multicolumn{2}{|c|}{ Average } & \multirow{2}{*}{$\begin{array}{c}\text { Flexural } \\
\text { Strength, } \sigma \\
\quad(M P a)\end{array}$} \\
\hline & $\begin{array}{l}\text { Maximum } \\
\text { Load (kN) }\end{array}$ & $\begin{array}{l}\text { Deflection } \\
\text { (mm) }\end{array}$ & \\
\hline 1 & 1.60 & 0.97 & 273 \\
\hline 2 & 16.06 & 4.20 & 2586 \\
\hline 3 & 48.18 & 14.64 & 7758 \\
\hline 4 & 31.36 & 9.72 & 5050 \\
\hline
\end{tabular}

\section{Discussion and Conclusions}

In general, the use of carbon fiber does strengthen brick wall panels against extreme impact. Brick Wall Panel Type 3 which was retrofitted with CFRP placed and epoxied in between the bricks and the mortar finishing showed minimal effects from extreme impact with only hair line cracks seen after the impact. The flexural strength of the material increased by 28 times compared to the un-retrofitted Brick Wall Panel Type 1. On the other hand, the Brick Wall Panel Type 4 which was retrofitted with CFRP placed on the mortar finishing showed hair line cracks after impact, but the cracks were worse than those of the Type 3 panels with the CFRP strips delaminating. The flexural strength of Brick Wall Panel Type 4 increased by 18 times compared to the un-retrofitted panel (Type 1). Thus, the Brick Wall Panel Type 3 performed better due to better bonding of the CFRP strip to the brick wall panel creating better resistance to extreme forces.

\section{References}

[1] Ehsani, M. and Pena, C.: Blast Loading Retrofit of Unreinforced Masonry Walls with Carbon Fiber Reinforced Polymer (CFRP), Structure Magazine, (2009), pp.16 - 20.

[2] De Lorenzis, L., Nanni, A., La Tegola, A.: Strengthening of Reinforced Concrete Structures with Near Surface Mounted FRP Rods. Bibl. International Meeting on Composite Materials, PLAST 2000, 9 - 11 May 2000, Milan, Italy.

[3] Zhuge, Y.: FRP - Retrofitted URM Walls Under In - Plane Review and Assessment of Available Models. Journals of Composites for Construction (C) ASCE, Vol.14(6), (2010), pp.743 - 753.

[4] Lamanna. A. J., Bank. L. C., Borowicz. D. T., Arora. D.: Strengthening of Concrete Beams with Mechanically Fastened FRP Strips. Unpublished Dissertation, University of Wisconsin, Madison, WI, USA. (2004)

[5] Nakaba K, Kanakubo T, Furuta T, Yoshizawa H.: Bond Behavior between Fiber Reinforced Polymer Laminates and Concrete, Vol. 98(34), (2001), pp.1 - 9.

[6] Teng, J.G., Chen, J.F., Smith. S.T. and Lam, L. (2002). FRP strengthened RC structures. West Sussex, England : John Wiley \& Sons.

[7] Mohd Azizul Mohd Noor: Investigation of Carbon Fiber Reinforced Polymer for Retrofitting Brick Wall against Impact Loading. B.Eng. Thesis, National Defence University of Malaysia, Kuala Lumpur (2011). 